Article

\title{
Devices for Ambulatory Monitoring of Sleep-Associated Disorders in Children with Neurological Diseases
}

\author{
Adriana Ulate-Campos ${ }^{1}$, Melissa Tsuboyama ${ }^{2}$ and Tobias Loddenkemper ${ }^{2, *}$ \\ 1 Department of Neurology, National Children's Hospital Dr. Carlos Saenz Herrera, 10103 San José, \\ Costa Rica; adrianaulate@hotmail.com \\ 2 Division of Epilepsy and Clinical Neurophysiology, Department of Neurology, Boston Children's Hospital, \\ Harvard Medical School, Boston, MA 02115, USA; melissa.tsuboyama@childrens.harvard.edu \\ * Correspondence: tobias.loddenkemper@childrens.harvard.edu
}

Received: 18 September 2017; Accepted: 18 December 2017; Published: 25 December 2017

\begin{abstract}
Good sleep quality is essential for a child's wellbeing. Early sleep problems have been linked to the later development of emotional and behavioral disorders and can negatively impact the quality of life of the child and his or her family. Sleep-associated conditions are frequent in the pediatric population, and even more so in children with neurological problems. Monitoring devices can help to better characterize sleep efficiency and sleep quality. They can also be helpful to better characterize paroxysmal nocturnal events and differentiate between nocturnal seizures, parasomnias, and obstructive sleep apnea, each of which has a different management. Overnight ambulatory detection devices allow for a tolerable, low cost, objective assessment of sleep quality in the patient's natural environment. They can also be used as a notification system to allow for rapid recognition and prompt intervention of events like seizures. Optimal monitoring devices will be patient- and diagnosis-specific, but may include a combination of modalities such as ambulatory electroencephalograms, actigraphy, and pulse oximetry. We will summarize the current literature on ambulatory sleep devices for detecting sleep disorders in children with neurological diseases.
\end{abstract}

Keywords: sleep monitoring; sleep devices; seizure detecting devices; SUDEP; pediatric sleep obstructive apnea; parasomnias; actigraphy; ambulatory polysomnography

\section{Introduction}

Good sleep quality is essential for a child's development, growth, memory, and ability to learn [1]. Sleep plays a role in normal synaptic development, neural plasticity, brain maturation, and memory consolidation during early development [2-4]. Additionally, early sleep problems have been linked to the later development of emotional and behavioral problems in animal models and in several childhood cohorts [5-9]. Short sleep duration and frequent nocturnal awakenings at 18 months of age may predict behavioral and emotional problems at five years of age [10].

Sleep-associated disorders affect approximately $25 \%$ of children. They are more frequent in children with neurological problems, and have been shown to affect the quality of life (QOL) of patients and their families [5,11-17]. While parents and caregivers can use sleep diaries to monitor their child's sleep habits, some details are often unaccounted for. Therefore, a monitoring device such as an actigraphy may help to better characterize sleep in patients at risk by tracking sleep onset latency, total sleep time, wake after sleep onset, sleep efficiency, and (tentatively) other events occurring during sleep and their frequency, allowing for more accurate data collection [18-21].

While a variety of pediatric sleep disorders exist, some of the conditions that require early diagnosis and treatment include nocturnal seizures, parasomnias, and obstructive sleep 
apnea $[12,22,23]$. Overnight detection devices may permit a more objective assessment of sleep quality and characterization of events, as well as earlier recognition and subsequent intervention in response to events such as obstructive sleep apnea and seizures. A variety of detection modalities are now available, including ambulatory electroencephalograms (AEEGs), electrocardiograms (EKGs), surface electromyography (sEMG), electrodermal activity (EDA) monitoring, actigraphy, video detection systems, mattress sensors, multimodal devices, nocturnal oximetry, and ambulatory polysomnography (PSG) that may be used as a single detection device, or in combination to further characterize sleep quality and paroxysmal nocturnal events [24-32]. Here, we will summarize the current literature regarding ambulatory sleep devices for monitoring sleep disorders in children with neurological diseases.

\section{Monitoring Sleep Quality}

Several neurological and neurodevelopmental syndromes present with sleep problems, including trisomy 21, Smith-Magenis syndrome, Rett syndrome, fragile- $X$ syndrome, Angelman syndrome, and Prader-Willi syndrome, as well as attention deficit hyperactivity disorder (ADHD), cerebral palsy, tuberous sclerosis, mucopolysaccharidoses, Niemann-Pick disease type $C$, and autism spectrum disorders (ASD), among others [14,33-37]. The most common complaints in these syndromes involve difficulties with sleep initiation, excessively fragmented sleep, frequent awakenings, sleep-disordered breathing, inverted circadian rhythm, problematic nighttime behaviors, and daytime sleepiness $[33,35,37]$. Sleep problems have been reported in up to $75-80 \%$ of children with ASD, almost three times the prevalence in the general population [15,17,38,39], and include problems with initiating and maintaining sleep, as well as anxiety-associated sleep behaviors [40]. Ambulatory tools used for monitoring sleep quality include sleep diaries and actigraphy. Ambulatory PSG may also be helpful and details will be provided in the obstructive sleep apnea section.

\subsection{Sleep Diaries}

Sleep diaries are often used to track the quality of sleep and response to interventions [14,33-37,41,42]. However, parents of normally developing children and adolescents may not be aware of sleep onset latency and night awakenings, or may report an idealized quality and quantity of sleep.

Children are more accurate in reporting their sleep habits and quality of sleep than parents, but in patients with severe neurodevelopmental disorders this may not be an alternative [43] There is a higher parental report of sleep problems and discrepancies with self-reports in children with ADHD, emphasizing the need for more objective measures [44-46]. Therefore, sleep diaries currently remain in use as a screening tool, but are being supplemented with wearable data obtained through, for example, actigraphy.

\subsection{Actigraphy}

Polysomnography remains the gold standard for assessing sleep quality, but the high cost and limited ability to provide information about one night of sleep outside of the child's habitual home environment limits its practicality. For this reason, actigraphy has been evaluated as an alternative or supplementary option. Actigraphy is a noninvasive, cost-effective monitoring method that assesses sleep quality through an accelerometer that analyzes movements in different axes. From this data, it is able to provide measurements of total sleep time, avoiding the recall bias related to sleep diaries $[47,48]$. A small wrist- or ankle-worn device houses the accelerometer. There have been several studies that have validated its use in the pediatric population, with the notable advantages of low cost, with reasonable tolerability over long periods of time, and functionality in terms of its use in the child's habitual sleep environment at home without major disruptions or distractions $[19,20,49,50]$. Actigraphy in children with ADHD is well tolerated, and has revealed higher motor activity, altered sleep efficiency, and prolonged sleep onset latency compared to normally developing children. Of note, sleep onset latency refers to the time it takes to transition from full wakefulness to sleep. This information obtained 
through actigraphy is comparable to that reported through PSG $[18,46,51]$. In one study, actigraphy was tolerated in 62 out of 69 children with ASD; only 7 patients refused to wear the actigraphs or removed them [40]. When compared to overnight home PSG, actigraphy has a sensitivity of $88 \%$ but specificity of $46 \%$ in children aged 5-12 years who were born prematurely [19]. In these sleep studies, sensitivity refers to the ability to detect true sleep and specificity to the ability to detect true wake [19]. Another study in 45 children ranging from 1 to 12 years old showed similar results, with a sensitivity of $90.1-97.7 \%$ and a specificity of $39.4-68.9 \%$ [49]. Studies assessing the use of actigraphy in patients with neurodevelopmental disorders, however, are scarce $[20,49,50]$. One study found that in children with ASD and developmental delay, the sensitivity of actigraphy was $97 \%$ and specificity was $24 \%$ [48]. The low specificity of actigraphy illustrates the main limitation of the device: its inability to distinguish movements during sleep from those of nocturnal awakenings [47-49].

\section{Parasomnias and Nocturnal Paroxysmal Events}

The most common paroxysmal nocturnal events in children with neurological disorders are parasomnias, and they form part of the differential diagnosis when ruling out epilepsy [39]. In one study, $29 \%$ of patients diagnosed with nocturnal frontal lobe epilepsy by polysomnography were originally referred for parasomnias [52]. Inpatient continuous video-electroencephalogram (EEG) monitoring is considered the gold standard for the diagnosis of epilepsy. However, given the high cost associated with the hospitalization required for this test, similar, more cost-effective and practical screening tests may also be performed in the ambulatory setting, i.e., ambulatory PSG or AEEG [53,54].

\section{Ambulatory Electroencephalogram}

Ambulatory electroencephalogram consists of continuous monitoring for $24 \mathrm{~h}$ or more in the outpatient setting. When the suspected event, parasomnia, non-epileptic event, or seizure, occurs multiple times per week, AEEG may provide a reasonable likelihood of recording events during a $24-48 \mathrm{~h}$ recording period $[55,56]$. In a prospective study of 64 children ranging from 0 to 17 years of age, AEEG aided in the diagnostic evaluation of $73 \%$ of the patients and helped to differentiate seizures from non-epileptic events in 61\% [53]. Addition of simultaneous video monitoring to view the semiology of the events facilitates interpretation of the electrographic recording, and ultimately the ability to differentiate between seizures and non-epileptic events. In children with neurological disorders, recording in the child's home environment may be preferred since it often results in better tolerance of the procedure, and may permit recording of the event. Although AEEG devices eliminate the need for hospitalization, patients may find these devices cumbersome because they involve leads placement on the head, and the leads are attached to a set of wires and a recording device. Patients often have difficulties tolerating these leads for more than a few days, and the quality of the EEG recording also tends to decline successively, unless families or technicians repair electrodes that may lose contact during recordings. Counseling families and training caregivers on how to maintain optimal EEG lead integrity for as long as possible is also paramount to obtaining technically satisfactory recordings [57]. Some of the disadvantages of this device include the inability for a medical provider to evaluate the child during an event, the lack of video in most cases, and the inability to readjust, reposition, or repair problematic electrodes during the recording [53]. Ultimately, the information AEEG provides often serves as an adequate screening step and compromise between obtaining a routine EEG that offers only limited information, and obtaining an inpatient continuous video-EEG study that may be more taxing on the patient and family. Thus, there is ongoing research to develop wireless EEG modalities that may be less cumbersome to handle [58-63]. One example, among many others, is a small two-electrode ambulatory EEG monitoring patch that is able to track and record EEG signals for up to seven days [64]. 


\section{Sleep-Related Epilepsy}

Epilepsy has an incidence of approximately $41-187 / 100,000$ per year in children, and 20-30\% of these patients will continue to have more than one seizure per month despite optimal medical management [65-69]. Patients with active epilepsy have a higher mortality than seizure-free patients with epilepsy [70-74]. There is an increased risk of sudden unexplained death in epilepsy (SUDEP) in patients with generalized tonic-clonic seizures (GTCS), while unsupervised in bed at night $[75,76]$. Both seizures and interictal discharges can be activated or potentiated in non-rapid eye movements (NREM) sleep in selected epilepsy conditions [77-80]. Several devices have been evaluated for the detection of nocturnal seizures. Seizure detection is more accurate when it combines more than one modality; multimodal systems have shown increased sensitivity and lower false detection ratios [81-86]. Modalities in addition to EEGs that may improve ambulatory detection rates of nocturnal seizures include: EKG, sEMG, EDA, actigraphy, video detection systems, and mattress sensors. Devices may provide accurate seizure quantification for selected seizures, tentatively permitting the sooner application of a rescue medication through earlier detection, or facilitating chrono-therapy regimens permitting treatment at times of greater seizure susceptibility based on the time pattern of detected seizures $[86,87]$.

\subsection{Ambulatory Electroencephalogram}

Video-electroencephalogram remains the gold standard for the diagnosis of epilepsy. Studies using algorithms for automatic EEG detection of seizures have revealed reasonable sensitivities for seizure detection [88-90]. Deployment of similar algorithms within an ambulatory EEG system could be used to detect nocturnal seizures at home. More information on AEEG is also provided in Section 3. Furthermore, a closed loop system could be developed in which the seizure is automatically detected by the EEG information by onboard processing and algorithms. Such a system would permit alerts, shortening the time to emergency interventions and treatment.

\subsection{Electrocardiogram}

Seizures can be associated with ictal tachycardia, tentatively making EKG a helpful ancillary detection modality. Cardiac arrhythmias and patterns such as T-wave alternans may also be associated with SUDEP, further supporting the use of EKG to detect seizures [91,92]. An EKG can be recorded from a single channel and has a higher signal-to-noise ratio than EEG [93]. Multimodal combination devices now include both an ultra-low power EKG sensor readout, and accelerometer for ambulatory monitoring of seizures. Other options utilize cardiac-based activated vagus nerve stimulation as part of a closed-loop system to detect seizures by delivering a stimulus when the heart rate is above a certain threshold; these may have an effect on seizure control and improvement in quality of life [94].

\subsection{Surface Electromyography}

Surface electromyography can also be used to detect the motor component of seizures [95]. Surface electromyography has good sensitivity for selected seizure types (ranging from 53 to 95\% for GTCS and tonic seizures), particularly when placed over the deltoid, biceps, and triceps muscles $[30,96,97]$. However, sEMG sensors may cause discomfort when strongly affixed to the skin and have the potential for detachment [97].

\subsection{Electrodermal Activity}

Electrodermal activity detects changes in sweat excretion and is thought to largely reflect activity of the sympathetic nervous system. Since many seizure types involve increased activation of the sympathetic nervous system, this transient increase in EDA serves as another parameter that may help detect nocturnal seizures, in particular generalized tonic-clonic seizures [31,98]. Electrodermal activity measurements taken from the ventral side of the distal forearm have been tolerated, even when 
applied for long periods of time [31]. However, EDA recordings are susceptible to pressure and motion artifacts. Studies on continuous ambulatory EDA monitoring are needed to provide information on how to optimize this modality both in the general population and in children with neurological diseases, as well as in specific seizure types beyond generalized tonic-clonic seizures.

\subsection{Actigraphy}

Actigraphy has been used to identify motor seizures by detecting changes in velocity and direction of movement [32,99-101]. Although differentiating seizures from repetitive movements can present a challenge, actigraphy has demonstrated good accuracy for detecting nocturnal seizures, with one study reporting detection of $78.5 \%$ of the seizures reported by parents [102]. Most patients and families also found such a device user-friendly $[32,99,101,103]$. The main limitation of this device is that its use is restricted to the detection of seizures with motor components. Additionally, if there is an obstacle to free limb movement during a seizure, the seizure may not be detected [32].

\subsection{Mattress Sensor Systems}

Mattress sensor systems consist of a sensor placed under the patient's mattress that is connected to a monitor with a detection algorithm. The device alerts caregivers when the sensor detects a stimulus above a set threshold or pattern [26-28]. One mattress sensor system had a sensitivity of $62.5 \%$ and a specificity of $90 \%$, while another had a sensitivity of $85 \%$ for detection of GTCS during sleep $[26,28,104]$. The disadvantages of mattress sensors are that they: (1) are best for detection of seizures with rhythmic movements; (2) often have a weight restriction; and (3) often have lower sensitivity compared to other devices $[27,28]$. Individual calibration for different movements during sleep, and testing over a couple of nights in a home setting are recommended and may permit individually improved results [26].

\subsection{Video and Sound Detection System}

A promising and popular seizure detection modality is related to video detection of seizures. They are divided into two categories: marker-based or marker-free [25]. Marker-free systems only detect seizures with a motor component and are limited to the area covered by video [25]. Marker-based systems place reference video fiducials on the head, trunk, or extremities to assess finer movements detected with infrared light. Because of the additional equipment required for marker-based systems, these may be uncomfortable, and the additional sensors may be disconnected or out of the detection area of the camera $[105,106]$. Video detection systems are best for recognition of seizures with large amplitude movements. Video detection may also include recording of sound, and acoustic baby monitoring systems are often also used in seizure patients, to permit detection of seizure-specific noises or vocalizations.

\subsection{Multimodal Devices}

Multimodal systems are proposed as alternatives to video-EEG monitoring because they combine two or more modalities, resulting in higher sensitivities and lower false detection ratios of many seizure types, while allowing for home monitoring [85]. For example, the combination of EDA and actigraphy improves detection of seizures with a motor component and autonomic involvement. A system with actigraphy and EDA placed on patients with GTCS during awake and sleep states yielded $94 \%$ sensitivity for seizure detection and one false alarm per $24 \mathrm{~h}$ [107]. The multi-modal intelligent seizure acquisition (MISA) system includes sEMG, magnetometers, actigraphy, and gyroscopes which allow for the assessment and characterization of full body movements [81]. The MISA system was first tested on individuals who simulated seizures. The person specific system detected all seizures, with only one false positive in a four hour time frame [83]. Some subjects found the system uncomfortable, and therefore smaller and fewer electrodes may likely be used in the next prototype [83,84].

Overall, EEG, actigraphy, sEMG, and video and sound detection, as well as EDA, are the modalities that have been most frequently used to date, with reasonable sensitivity for generalized 
tonic-clonic seizures in many cases [86]. There is abundant ongoing research in this field which hopefully will introduce more sensitive multimodal devices that can be tailored to individual characteristics, neurological conditions and seizure types.

\section{Obstructive Sleep Apnea}

Pediatric obstructive sleep apnea (OSA) is defined as a breathing disorder during sleep characterized by prolonged partial or complete upper airway obstruction that disrupts both normal ventilation during sleep and normal sleep patterns [108,109]. Its prevalence in the pediatric population is up to $5.7 \%$ [109]. A meta-analysis of 350 studies found that OSA in children was linked to deficits in cognition and neurophysiological function [109]. Deficits in executive functions and memory were the most common cognitive problems, and hyperactivity was the most common behavior abnormality [109-112]. Nocturnal, in-laboratory PSG is the gold standard for diagnosing OSA, but some lower cost alternatives including sleep questionnaires, nocturnal oximetry, and home-based PSG have been evaluated $[109,113]$. These options may be preferred in some patients as a screening tool, especially in children with neurodevelopmental disorders as they are able to remain in a familiar environment.

\subsection{Sleep Questionnaires for Obstructive Sleep Apnea}

Sleep questionnaires are offered as a simple, low cost alternative to detect pediatric OSA. The Pediatric Sleep Questionnaire is a 22-item sleep-related breathing disorder tool that centers on behavioral problems, excessive daytime sleepiness, and snoring. However, this questionnaire had a sensitivity of $78 \%$ and specificity of $72 \%$, limiting its ability to be used as a surrogate for PSG [114]. Instead, sleep questionnaires can be used as a screening tool to identify patients who require additional diagnostic testing [109].

\subsection{Home Oximetry}

Home oximetry has the advantage of being of lower cost and more readily available than PSGs, which often have long wait-lists. One study found the use of home oximetry in healthy children older than 4 years old to have a sensitivity of $67 \%$ and a specificity of $60 \%$ [115]. Other studies have found the use of oximeters to have higher specificity but lower sensitivity in diagnosing pediatric OSA [24]. One study in children with a median age of 4 years found that $78 \%$ of recordings were either normal or non-conclusive, requiring a subsequent PSG [116]. A major contributor to the poor sensitivity and specificity of this device is oximetry movement artifact that results from frequent movements of children at night. Phone oximetry is yet another portable, easy to use screening tool with a sensitivity of $88 \%$ and a specificity of $83 \%$ in diagnosing OSA [117]. Ultimately, home oximetry may serve as another screening tool to be used in children with sleep disordered breathing to identify those who require a PSG or to estimate the severity of pre-existing OSA [116,118]. Alternatively, it can be used in combination with other devices such as an accelerometer and EKG for home monitoring of sleep-disordered breathing. Validation trials to identify the best combination of devices are still needed [119]. There is no single statistic on the number of children with neurologic disorders with OSA who do not suffer from desaturations, but more widespread use of portable devices may provide such data soon [120].

\subsection{Ambulatory Polysomnography}

Ambulatory PSG refers to unattended sleep studies conducted at home. This testing approach can produce good quality recordings, is well-tolerated, and is less disruptive to the patient's schedule $[109,121,122]$. It is also less costly than an in-laboratory PSG. Ambulatory PSG was performed in a large cohort of 157 children from 5-12 years of age in the TuCASA study which demonstrated that ambulatory PSG recordings could be of high quality and not disruptive to sleep [122]. Five of these children also had in-laboratory PSG, and the results were comparable to those on the ambulatory PSG. 
Ninety-one percent of recordings were deemed of acceptable quality after the initial attempt. Similar findings were obtained by another study that assessed the feasibility of performing ambulatory PSG in children by performing this procedure in 201 ex-preterm children 5-12 years of age, including children with cerebral palsy or developmental delays. Ninety-one percent of cases had satisfactory recordings, and nearly all children tolerated the procedure well. The median parental satisfaction on a Likert scale was 1 (range $1-5$, with 1 being best), and a median rating of 0 on the pediatric Likert scale (range $0-5$, with 0 being the best) [121]. None of the participating centers had prior experience with ambulatory PSG and still achieved very good quality recordings that further improved in quality over 4 years of testing. In this particular study, technicians went to the home to set up the equipment including a full PSG montage, which likely contributed to the good quality of recordings. Access to these resources may not be widely available [121]. As feasibility has been shown, additional studies are now needed to validate ambulatory PSG as a diagnostic tool for OSA.

Children with ASD or anxiety are more likely to have difficulties tolerating most procedures, including ambulatory PSG, because of the unexpected sensory stimulus the equipment may produce or because of the novelty of the procedure. A desensitization protocol implemented in children with ASD and developmental delay was found to be successful in $86 \%$ of children with ASD and in $87 \%$ of those with developmental delay [123]. More widespread use of this desensitization protocol may be helpful to increase the likelihood of tolerability of this procedure in children, particularly in those with neurodevelopmental conditions [123].

\section{Challenges and Future Directions}

One of the main challenges in the development of an ambulatory device suitable for monitoring sleep in children with neurological disorders is the great number and variability of neurological disorders. However, once devices become more widely used, additional data on more rare conditions will become available. Another challenge may be increased sensitivity to devices in skin contact, as seen in allergic conditions or with autistic spectrum disorders, and many children with neurologic comorbidities may be hyperactive or hypersensitive to tactile stimuli. This highlights the importance that the device should be wireless, miniaturized, lightweight, and with minimal electrodes/skin contact. The ideal monitoring device should also be safe, comfortable, easy to use, and cause minimal disruption for patients, their caregivers, and — as applicable—for the medical staff using the device. Another important challenge is the limited number of studies regarding ambulatory sleep monitoring, and the great diversity in terms of research methodology among them. Nonetheless, all of the available information indicates that the optimal device for monitoring the quality of sleep should include a combination of sensor modalities, since multimodal devices are more sensitive than the isolated individual sensors. The optimal combination of modalities may need to be individualized based on the clinical patient presentation and the clinical question at hand. Devices may present with onboard processing and algorithms to detect an event, and could trigger an alarm that alerts caregivers and permits proper management. Finally, collaboration between patients, caregivers, physicians, and researchers may allow the development of devices that fulfill most of the requirements for it to be useful. This may also allow uniformity of research and improve the quality of the information provided.

\section{Conclusions}

The optimal device for ambulatory monitoring sleep in children with neurological conditions should be patient- and disease-specific, comfortable, and should involve a combination of detection modalities. We provided a table as a summary and quick reference guide to devices and indications for their use (Table 1). These devices are currently under development, and are urgently needed to respond to tentative emergencies quickly, and to minimize long-term consequences of chronic conditions. 
Table 1. Suggestions for monitoring of sleep and related indications with portable devices (choices are not exclusive, and may vary based on available resources and physician preference).

\begin{tabular}{|c|c|c|c|c|c|c|c|c|c|c|c|c|}
\hline \multirow[b]{2}{*}{ Indication } & \multicolumn{12}{|c|}{ Device/Instrument } \\
\hline & Actigraphy & $\begin{array}{c}\text { Ambulatory } \\
\text { EEG }\end{array}$ & $\begin{array}{c}\text { Ambulatory } \\
\text { PSG }\end{array}$ & EDA & EKG & $\begin{array}{c}\text { Home } \\
\text { Oximetry }\end{array}$ & $\begin{array}{l}\text { Mattress } \\
\text { Sensor } \\
\text { Systems }\end{array}$ & $\begin{array}{l}\text { Sleep } \\
\text { Diary }\end{array}$ & $\begin{array}{c}\text { Sleep } \\
\text { Questionnaire }\end{array}$ & sEMG & $\begin{array}{l}\text { Video } \\
\text { Systems }\end{array}$ & $\begin{array}{l}\text { Multimodal } \\
\text { Devices }\end{array}$ \\
\hline Sleep quality & $x$ & & $x$ & & & & & $X$ & $x$ & & & $x$ \\
\hline Parasomnias & & $x$ & & & & & & & & & $x$ & $X$ \\
\hline $\begin{array}{c}\text { Nocturnal } \\
\text { epilepsy }\end{array}$ & $x$ & $x$ & & $x$ & $x$ & $x$ & $x$ & & & $x$ & $x$ & $x$ \\
\hline $\begin{array}{l}\text { Obstructive } \\
\text { sleep apnea }\end{array}$ & & & $x$ & & & $x$ & & & $x$ & & & $x$ \\
\hline
\end{tabular}

EEG: electroencephalogram; EDA: electrodermal activity; EKG: electrocardiogram; PSG: polysomnography; sEMG: surface electromyography. 
Acknowledgments: This article is funded by the Epilepsy Research Fund.

Author Contributions: Adriana Ulate-Campos performed the literature search and literature revision, participated in study design, drafted the manuscript, reviewed, and edited for important intellectual content. Melissa Tsuboyama participated in the interpretation of data in the literature, reviewed, and edited the manuscript for important intellectual content. Tobias Loddenkemper developed the original concept and study design of the manuscript, participated in the interpretation and analysis of data in the literature, reviewed, and edited the manuscript for important intellectual content. All authors gave approval to the final version of the manuscript to be submitted and all authors are in agreement to be accountable for all aspects of the work in ensuring that questions related to the accuracy or integrity of any part of the work are appropriately investigated and resolved.

Conflicts of Interest: Tobias Loddenkemper's research laboratory works with device donations from several companies, including Empatica, SmartWatch, and Epitel, among others. He is part of several pending patent application regarding epilepsy diagnosis, seizure detection, and seizure prediction. He serves on the Laboratory Accreditation Board for Long Term (Epilepsy and Intensive Care Unit) Monitoring, on the Council (and as Vice President) of the American Clinical Neurophysiology Society, on the American Board of Clinical Neurophysiology, as an Associate Editor for Seizure, and as an Associate Editor for Wyllie's Treatment of Epilepsy (6th and 7th edition). He receives research support from National Institutes of Health (NIH), the Epilepsy Research Fund, the American Epilepsy Society, the Epilepsy Foundation of America, the Epilepsy Therapy Project, and the Pediatric Epilepsy Research Foundation, and has received research grants from Lundbeck, Eisai, Upsher-Smith, Acorda, Mallinckrodt, Sage, and Pfizer. He serves as a consultant for Zogenix, Engage, Upsher Smith, Amzell, Eisai, Sunovion, and Lundbeck. He has received speaker honorariums from national societies including the American Academy of Neurology, American Epilepsy Society and American Clinical Neurophysiology Society, and for grand rounds at various academic centers. He performs long-term video electroencephalogram and Intensive Care Unit (ICU) monitoring, electroencephalograms, and other electrophysiological studies at Boston Children's Hospital and affiliated hospitals, and bills for these procedures. He evaluates pediatric neurology patients and bills for clinical care. His wife, Karen Stannard, is a pediatric neurologist and she performs long-term video electroencephalogram and ICU monitoring, electroencephalograms, and other electrophysiological studies, and bills for these procedures. She evaluates pediatric neurology patients and bills for clinical care. The funding sponsors had no role in the design of the study; in the collection, analyses, or interpretation of data; in the writing of the manuscript, and in the decision to publish the results.

\section{References}

1. Martin, J.; Hiscock, H.; Hardy, P.; Davey, B.; Wake, M. Adverse associations of infant and child sleep problems and parent health: An Australian population study. Pediatrics 2007, 119, 947-955. [CrossRef] [PubMed]

2. Picchioni, D.; Reith, R.M.; Nadel, J.L.; Smith, C.B. Sleep, plasticity and the pathophysiology of neurodevelopmental disorders: The potential roles of protein synthesis and other cellular processes. Brain Sci. 2014, 4, 150-201. [CrossRef] [PubMed]

3. Peirano, P.D.; Algarin, C.R. Sleep in brain development. Biol. Res. 2007, 40, 471-478. [CrossRef] [PubMed]

4. Wilhelm, I.; Prehn-Kristensen, A.; Born, J. Sleep-dependent memory consolidation-What can be learnt from children? Neurosci. Biobehav. Rev. 2012, 36, 1718-1728. [CrossRef] [PubMed]

5. Hysing, M.; Harvey, A.G.; Torgersen, L.; Ystrom, E.; Reichborn-Kjennerud, T.; Sivertsen, B. Trajectories and predictors of nocturnal awakenings and sleep duration in infants. J. Dev. Behav. Pediatr. 2014, 35, 309-316. [CrossRef] [PubMed]

6. Gregory, A.M.; O'Connor, T.G. Sleep problems in childhood: A longitudinal study of developmental change and association with behavioral problems. J. Am. Acad. Child Adolesc. Psychiatry 2002, 41, 964-971. [CrossRef] [PubMed]

7. O'Callaghan, F.V.; Al Mamun, A.; O'Callaghan, M.; Clavarino, A.; Williams, G.M.; Bor, W.; Heussler, H.; Najman, J.M. The link between sleep problems in infancy and early childhood and attention problems at 5 and 14 years: Evidence from a birth cohort study. Early Hum. Dev. 2010, 86, 419-424. [CrossRef] [PubMed]

8. Sare, R.M.; Levine, M.; Hildreth, C.; Picchioni, D.; Smith, C.B. Chronic sleep restriction during development can lead to long-lasting behavioral effects. Physiol. Behav. 2016, 155, 208-217. [CrossRef] [PubMed]

9. Fisher, H.L.; Lereya, S.T.; Thompson, A.; Lewis, G.; Zammit, S.; Wolke, D. Childhood parasomnias and psychotic experiences at age 12 years in a United Kingdom birth cohort. Sleep 2014, 37, 475-482. [CrossRef] [PubMed]

10. Sivertsen, B.; Harvey, A.G.; Reichborn-Kjennerud, T.; Torgersen, L.; Ystrom, E.; Hysing, M. Later emotional and behavioral problems associated with sleep problems in toddlers: A longitudinal study. JAMA Pediatr. 2015, 169, 575-582. [CrossRef] [PubMed] 
11. Kim, D.S.; Lee, C.L.; Ahn, Y.M. Sleep problems in children and adolescents at pediatric clinics. Korean J. Pediatr. 2017, 60, 158-165. [CrossRef] [PubMed]

12. Licis, A. Sleep Disorders: Assessment and Treatment in Preschool-Aged Children. Child Adolesc. Psychiatr. Clin. N. Am. 2017, 26, 587-595. [CrossRef] [PubMed]

13. Uebergang, L.K.; Arnup, S.J.; Hiscock, H.; Care, E.; Quach, J. Sleep problems in the first year of elementary school: The role of sleep hygiene, gender and socioeconomic status. Sleep Health 2017, 3, 142-147. [CrossRef] [PubMed]

14. Gail Williams, P.; Sears, L.L.; Allard, A. Sleep problems in children with autism. J. Sleep Res. 2004, 13, $265-268$. [CrossRef] [PubMed]

15. Owens, J. Classification and epidemiology of childhood sleep disorders. Prim. Care 2008, 35, 533-546. [CrossRef] [PubMed]

16. Mindell, J.A.; Owens, J.A.; Carskadon, M.A. Developmental features of sleep. Child Adolesc. Psychiatr. Clin. N. Am. 1999, 8, 695-725. [PubMed]

17. Richdale, A.L.; Schreck, K.A. Sleep problems in autism spectrum disorders: Prevalence, nature, \& possible biopsychosocial aetiologies. Sleep Med. Rev. 2009, 13, 403-411. [PubMed]

18. De Crescenzo, F.; Licchelli, S.; Ciabattini, M.; Menghini, D.; Armando, M.; Alfieri, P.; Mazzone, L.; Pontrelli, G.; Livadiotti, S.; Foti, F.; et al. The use of actigraphy in the monitoring of sleep and activity in ADHD: A meta-analysis. Sleep Med. Rev. 2016, 26, 9-20. [CrossRef] [PubMed]

19. Meltzer, L.J.; Wong, P.; Biggs, S.N.; Traylor, J.; Kim, J.Y.; Bhattacharjee, R.; Narang, I.; Marcus, C.L. Validation of Actigraphy in Middle Childhood. Sleep 2016, 39, 1219-1224. [CrossRef] [PubMed]

20. Meltzer, L.J.; Hiruma, L.S.; Avis, K.; Montgomery-Downs, H.; Valentin, J. Comparison of a Commercial Accelerometer with Polysomnography and Actigraphy in Children and Adolescents. Sleep 2015, 38, 1323-1330. [CrossRef] [PubMed]

21. Roane, B.M.; Van Reen, E.; Hart, C.N.; Wing, R.; Carskadon, M.A. Estimating sleep from multisensory armband measurements: Validity and reliability in teens. J. Sleep Res. 2015, 24, 714-721. [CrossRef] [PubMed]

22. Zucconi, M.; Bruni, O. Sleep disorders in children with neurologic diseases. Semin. Pediatr. Neurol. 2001, 8, 258-275. [CrossRef] [PubMed]

23. Kohrman, M.H.; Carney, P.R. Sleep-related disorders in neurologic disease during childhood. Pediatr. Neurol. 2000, 23, 107-113. [CrossRef]

24. Tan, H.L.; Kheirandish-Gozal, L.; Gozal, D. Pediatric Home Sleep Apnea Testing: Slowly Getting There! Chest 2015, 148, 1382-1395. [CrossRef] [PubMed]

25. Pediaditis, M.; Tsiknakis, M.; Leitgeb, N. Vision-based motion detection, analysis and recognition of epileptic seizures-A systematic review. Comput. Methods Programs Biomed. 2012, 108, 1133-1148. [CrossRef] [PubMed]

26. Carlson, C.; Arnedo, V.; Cahill, M.; Devinsky, O. Detecting nocturnal convulsions: Efficacy of the MP5 monitor. Seizure 2009, 18, 225-227. [CrossRef] [PubMed]

27. Fulton, S.; Poppel, K.V.; McGregor, A.; Ellis, M.; Patters, A.; Wheless, J. Prospective Study of 2 Bed Alarms for Detection of Nocturnal Seizures. J. Child Neurol. 2012, 28, 1430-1433. [CrossRef] [PubMed]

28. Poppel, K.V.; Fulton, S.P.; McGregor, A.; Ellis, M.; Patters, A.; Wheless, J. Prospective Study of the Emfit Movement Monitor. J. Child Neurol. 2013, 28, 1434-1436. [CrossRef] [PubMed]

29. Romero, I.; Grundlehner, B.; Penders, J. Robust beat detector for ambulatory cardiac monitoring. In Proceedings of the 2009 Annual International Conference of the IEEE Engineering in Medicine and Biology Society, Minneapolis, MN, USA, 3-6 September 2009; pp. 950-953.

30. Conradsen, I.; Beniczky, S.; Hoppe, K.; Wolf, P.; Sorensen, H.B. Automated algorithm for generalized tonic-clonic epileptic seizure onset detection based on sEMG zero-crossing rate. IEEE Trans. Biomed. Eng. 2012, 59, 579-585. [CrossRef] [PubMed]

31. Poh, M.Z.; Swenson, N.C.; Picard, R.W. A wearable sensor for unobtrusive, long-term assessment of electrodermal activity. IEEE Trans. Biomed. Eng. 2010, 57, 1243-1252. [PubMed]

32. Beniczky, S.; Polster, T.; Kjaer, T.W.; Hjalgrim, H. Detection of generalized tonic-clonic seizures by a wireless wrist accelerometer: A prospective, multicenter study. Epilepsia 2013, 54, e58-e61. [CrossRef] [PubMed]

33. Angriman, M.; Caravale, B.; Novelli, L.; Ferri, R.; Bruni, O. Sleep in children with neurodevelopmental disabilities. Neuropediatrics 2015, 46, 199-210. [CrossRef] [PubMed]

34. Stores, G. Sleep studies in children with a mental handicap. J. Child Psychol. Psychiatry 1992, 33, $1303-1317$. [CrossRef] [PubMed] 
35. Kotagal, S. Sleep in Neurodevelopmental and Neurodegenerative Disorders. Semin. Pediatr. Neurol. 2015, 22, 126-129. [CrossRef] [PubMed]

36. Souders, M.C.; Zavodny, S.; Eriksen, W.; Sinko, R.; Connell, J.; Kerns, C.; Schaaf, R.; Pinto-Martin, J. Sleep in Children with Autism Spectrum Disorder. Curr. Psychiatry Rep. 2017, 19, 34. [CrossRef] [PubMed]

37. Robinson-Shelton, A.; Malow, B.A. Sleep Disturbances in Neurodevelopmental Disorders. Curr. Psychiatry Rep. 2016, 18, 6. [CrossRef] [PubMed]

38. Richdale, A.L. Sleep problems in autism: Prevalence, cause, and intervention. Dev. Med. Child Neurol. 1999, 41, 60-66. [CrossRef] [PubMed]

39. Maski, K.; Owens, J.A. Insomnia, parasomnias, and narcolepsy in children: Clinical features, diagnosis, and management. Lancet Neurol. 2016, 15, 1170-1181. [CrossRef]

40. Wiggs, L.; Stores, G. Sleep patterns and sleep disorders in children with autistic spectrum disorders: Insights using parent report and actigraphy. Dev. Med. Child Neurol. 2004, 46, 372-380. [CrossRef] [PubMed]

41. Hannan, K.; Hiscock, H. Sleep problems in children. Aust. Fam. Physician 2015, 44, 880-883. [PubMed]

42. Moreno, M.A. Sleep Terrors and Sleepwalking: Common Parasomnias of Childhood. JAMA Pediatr. 2015, 169, 704. [CrossRef] [PubMed]

43. Owens, J.A.; Spirito, A.; McGuinn, M.; Nobile, C. Sleep habits and sleep disturbance in elementary school-aged children. J. Dev. Behav. Pediatr. 2000, 21, 27-36. [CrossRef] [PubMed]

44. Corkum, P.; Tannock, R.; Moldofsky, H.; Hogg-Johnson, S.; Humphries, T. Actigraphy and parental ratings of sleep in children with attention-deficit/hyperactivity disorder (ADHD). Sleep 2001, 24, 303-312. [CrossRef] [PubMed]

45. Wiggs, L.; Montgomery, P.; Stores, G. Actigraphic and parent reports of sleep patterns and sleep disorders in children with subtypes of attention-deficit hyperactivity disorder. Sleep 2005, 28, 1437-1445. [CrossRef] [PubMed]

46. Owens, J.; Sangal, R.B.; Sutton, V.K.; Bakken, R.; Allen, A.J.; Kelsey, D. Subjective and objective measures of sleep in children with attention-deficit/hyperactivity disorder. Sleep Med. 2009, 10, 446-456. [CrossRef] [PubMed]

47. Sadeh, A. The role and validity of actigraphy in sleep medicine: An update. Sleep Med. Rev. 2011, 15, $259-267$. [CrossRef] [PubMed]

48. Sitnick, S.L.; Goodlin-Jones, B.L.; Anders, T.F. The use of actigraphy to study sleep disorders in preschoolers: Some concerns about detection of nighttime awakenings. Sleep 2008, 31, 395-401. [CrossRef] [PubMed]

49. Hyde, M.; O’Driscoll, D.M.; Binette, S.; Galang, C.; Tan, S.K.; Verginis, N.; Davey, M.J.; Horne, R.S. Validation of actigraphy for determining sleep and wake in children with sleep disordered breathing. J. Sleep Res. 2007, 16, 213-216. [CrossRef] [PubMed]

50. Meltzer, L.J.; Walsh, C.M.; Traylor, J.; Westin, A.M. Direct comparison of two new actigraphs and polysomnography in children and adolescents. Sleep 2012, 35, 159-166. [CrossRef] [PubMed]

51. Gruber, R.; Xi, T.; Frenette, S.; Robert, M.; Vannasinh, P.; Carrier, J. Sleep disturbances in prepubertal children with attention deficit hyperactivity disorder: A home polysomnography study. Sleep 2009, 32, 343-350. [CrossRef] [PubMed]

52. Miano, S.; Peraita-Adrados, R. Nocturnal frontal lobe epilepsy is often misdiagnosed as sleep disorders in children: A case series. Rev. Neurol. 2013, 56, 257-267. [PubMed]

53. Wirrell, E.; Kozlik, S.; Tellez, J.; Wiebe, S.; Hamiwka, L. Ambulatory electroencephalography (EEG) in children: Diagnostic yield and tolerability. J. Child Neurol. 2008, 23, 655-662. [CrossRef] [PubMed]

54. Faulkner, H.J.; Arima, H.; Mohamed, A. The utility of prolonged outpatient ambulatory EEG. Seizure 2012, 21, 491-495. [CrossRef] [PubMed]

55. Olson, D.M. Success of ambulatory EEG in children. J. Clin. Neurophysiol. 2001, 18, 158-161. [CrossRef] [PubMed]

56. Foley, C.M.; Legido, A.; Miles, D.K.; Grover, W.D. Diagnostic value of pediatric outpatient video-EEG. Pediatr. Neurol. 1995, 12, 120-124. [CrossRef]

57. Foley, C.M.; Legido, A.; Miles, D.K.; Chandler, D.A.; Grover, W.D. Long-term computer-assisted outpatient electroencephalogram monitoring in children and adolescents. J. Child Neurol. 2000, 15, 49-55. [CrossRef] [PubMed]

58. Luan, B.; Sun, M. A Simulation Study on a Single-Unit Wireless EEG Sensor. In Proceedings of the 201541 st Annual Northeast Biomedical Engineering Conference (NEBEC), Troy, NY, USA, 17-19 April 2015. 
59. Luan, B.; Jia, W.; Thirumala, P.D.; Balzer, J.; Gao, D.; Sun, M. A Feasibility Study on a Single-Unit Wireless EEG Sensor. In Proceedings of the 2014 12th International Conference on Signal Processing (ICSP), Hangzhou, China, 19-23 October 2014; pp. 2282-2285.

60. Wyckoff, S.N.; Sherlin, L.H.; Ford, N.L.; Dalke, D. Validation of a wireless dry electrode system for electroencephalography. J. Neuroeng. Rehabil. 2015, 12, 95. [CrossRef] [PubMed]

61. Do Valle, B.G.; Cash, S.S.; Sodini, C.G. Wireless behind-the-ear EEG recording device with wireless interface to a mobile device (iPhone/iPod touch). In Proceedings of the 2014 36th Annual International Conference of the IEEE Engineering in Medicine and Biology Society, Chicago, IL, USA, 26-30 August 2014; pp. 5952-5955.

62. Mihajlovic, V.; Grundlehner, B.; Vullers, R.; Penders, J. Wearable, wireless EEG solutions in daily life applications: What are we missing? IEEE J. Biomed. Health Inform. 2015, 19, 6-21. [CrossRef] [PubMed]

63. Grant, A.C.; Abdel-Baki, S.G.; Omurtag, A.; Sinert, R.; Chari, G.; Malhotra, S.; Weedon, J.; Fenton, A.A.; Zehtabchi, S. Diagnostic accuracy of microEEG: A miniature, wireless EEG device. Epilepsy Behav. 2014, 34, 81-85. [CrossRef] [PubMed]

64. Lehmkuhle, M.; Elwood, M.; Wheeler, J.; Fisher, F.; Dudek, E. Development of a discrete, wearable, EEG device for counting seizures (abstract). In Proceedings of the 69th Annual Meeting of the American Epilepsy Society, Philadelphia, PA, USA, 4-8 December 2015.

65. Forsgren, L. Prevalence of epilepsy in adults in northern Sweden. Epilepsia 1992, 33, 450-458. [CrossRef] [PubMed]

66. Forsgren, L.; Beghi, E.; Oun, A.; Sillanpaa, M. The epidemiology of epilepsy in Europe-A systematic review. Eur. J. Neurol. 2005, 12, 245-253. [CrossRef] [PubMed]

67. Sidenvall, R.; Forsgren, L.; Heijbel, J. Prevalence and characteristics of epilepsy in children in northern Sweden. Seizure 1996, 5, 139-146. [CrossRef]

68. Kwan, P.; Brodie, M.J. Early identification of refractory epilepsy. N. Engl. J. Med. 2000, 342, 314-319. [CrossRef] [PubMed]

69. Camfield, P.; Camfield, C. Incidence, prevalence and aetiology of seizures and epilepsy in children. Epileptic Disord. 2015, 17, 117-123. [PubMed]

70. Christensen, J.; Pedersen, C.B.; Sidenius, P.; Olsen, J.; Vestergaard, M. Long-term mortality in children and young adults with epilepsy-A population-based cohort study. Epilepsy Res. 2015, 114, 81-88. [CrossRef] [PubMed]

71. Bell, G.S.; Sinha, S.; Tisi, J.; Stephani, C.; Scott, C.A.; Harkness, W.F.; McEvoy, A.W.; Peacock, J.L.; Walker, M.C.; Smith, S.J.; et al. Premature mortality in refractory partial epilepsy: Does surgical treatment make a difference? J. Neurol. Neurosurg. Psychiatry 2010, 81, 716-718. [CrossRef] [PubMed]

72. Holst, A.G.; Winkel, B.G.; Risgaard, B.; Nielsen, J.B.; Rasmussen, P.V.; Haunso, S.; Sabers, A.; Uldall, P.; Tfelt-Hansen, J. Epilepsy and risk of death and sudden unexpected death in the young: A nationwide study. Epilepsia 2013, 54, 1613-1620. [CrossRef] [PubMed]

73. Nashef, L.; Fish, D.R.; Sander, J.W.; Shorvon, S.D. Incidence of sudden unexpected death in an adult outpatient cohort with epilepsy at a tertiary referral centre. J. Neurol. Neurosurg. Psychiatry 1995, 58, 462-464. [CrossRef] [PubMed]

74. Sillanpaa, M.; Shinnar, S. SUDEP and other causes of mortality in childhood-onset epilepsy. Epilepsy Behav. 2013, 28, 249-255. [CrossRef] [PubMed]

75. Lamberts, R.J.; Thijs, R.D.; Laffan, A.; Langan, Y.; Sander, J.W. Sudden unexpected death in epilepsy: People with nocturnal seizures may be at highest risk. Epilepsia 2012, 53, 253-257. [CrossRef] [PubMed]

76. Langan, Y.; Nashef, L.; Sander, J.W. Case-control study of SUDEP. Neurology 2005, 64, 1131-1133. [CrossRef] [PubMed]

77. Malow, A.; Bowes, R.J.; Ross, D. Relationship of temporal lobe seizures to sleep and arousal: A combined scalp-intracranial electrode study. Sleep 2000, 23, 231-234. [CrossRef] [PubMed]

78. Malow, B.A.; Lin, X.; Kushwaha, R.; Aldrich, M.S. Interictal spiking increases with sleep depth in temporal lobe epilepsy. Epilepsia 1998, 39, 1309-1316. [CrossRef] [PubMed]

79. Bazil, C.W.; Walczak, T.S. Effects of sleep and sleep stage on epileptic and nonepileptic seizures. Epilepsia 1997, 38, 56-62. [CrossRef] [PubMed]

80. St Louis, E.K. Sleep and Epilepsy: Strange Bedfellows No More. Minerva Pneumol. 2011, 50, $159-176$. [PubMed] 
81. Conradsen, I.; Beniczky, S.; Wolf, P.; Kjaer, T.W.; Sams, T.; Sorensen, H.B. Automatic multi-modal intelligent seizure acquisition (MISA) system for detection of motor seizures from electromyographic data and motion data. Comput. Methods Programs Biomed. 2012, 107, 97-110. [CrossRef] [PubMed]

82. Milosevic, M.; Van de Vel, A.; Bonroy, B.; Ceulemans, B.; Lagae, L.; VanRumste, B.; Van Huffel, S. Automated Detection of Tonic-Clonic Seizures using 3D Accelerometry and Surface Electromyography in Pediatric Patients. IEEE J. Biomed. Health Inform. 2016, 20, 1333-1341. [CrossRef] [PubMed]

83. Conradsen, I.; Beniczky, S.; Wolf, P.; Terney, D.; Sams, T.; Sorensen, H.B. Multi-modal intelligent seizure acquisition (MISA) system-A new approach towards seizure detection based on full body motion measures. In Proceedings of the 2009 Annual International Conference of the IEEE Engineering in Medicine and Biology Society, Minneapolis, MN, USA, 3-6 September 2009; pp. 2591-2595.

84. Conradsen, I.; Beniczky, S.; Wolf, P.; Henriksen, J.; Sams, T.; Sorensen, H.B. Seizure onset detection based on a Uni- or multi-modal intelligent seizure acquisition (UISA/MISA) system. In Proceedings of the 2010 Annual International Conference of the IEEE Engineering in Medicine and Biology, Buenos Aires, Argentina, 31 August-4 September 2010; pp. 3269-3272.

85. Van de Vel, A.; Cuppens, K.; Bonroy, B.; Milosevic, M.; Jansen, K.; Van Huffel, S.; Vanrumste, B.; Cras, P.; Lagae, L.; Ceulemans, B. Non-EEG seizure detection systems and potential SUDEP prevention: State of the art: Review and update. Seizure 2016, 41, 141-153. [CrossRef] [PubMed]

86. Ulate-Campos, A.; Coughlin, F.; Gainza-Lein, M.; Fernandez, I.S.; Pearl, P.L.; Loddenkemper, T. Automated seizure detection systems and their effectiveness for each type of seizure. Seizure 2016, 40, 88-101. [CrossRef] [PubMed]

87. Ramgopal, S.; Thome-Souza, S.; Jackson, M.; Kadish, N.E.; Sanchez Fernandez, I.; Klehm, J.; Bosl, W.; Reinsberger, C.; Schachter, S.; Loddenkemper, T. Seizure detection, seizure prediction, and closed-loop warning systems in epilepsy. Epilepsy Behav. 2014, 37, 291-307. [CrossRef] [PubMed]

88. Kim, H.; Rosen, J. Epileptic seizure detection-An AR model based algorithm for implantable device. In Proceedings of the 2010 Annual International Conference of the IEEE Engineering in Medicine and Biology, Buenos Aires, Argentina, 31 August-4 September 2010; pp. 5541-5544.

89. Gotman, J. Automatic seizure detection: Improvements and evaluation. Electroencephalogr. Clin. Neurophysiol. 1990, 76, 317-324. [CrossRef]

90. Teixeira, C.; Direito, B.; Bandarabadi, M.; Le Van Quyen, M.; Valderrama, M.; Schelter, B.; Schulze-Bonhage, A.; Navarro, V.; Sales, F.; Dourado, A. Epileptic seizure predictors based on computational intelligence techniques: A comparative study with 278 patients. Comput. Methods Programs Biomed. 2014, 114, 324-336. [CrossRef] [PubMed]

91. Verrier, R.L.; Schachter, S.C. Neurocardiac interactions in sudden unexpected death in epilepsy: Can ambulatory electrocardiogram-based assessment of autonomic function and T-wave alternans help to evaluate risk. In Sudden Unexpected Death in Epilepsy: Mechanisms and New Methods for Analyzing Risks; Taylor and Francis: Boca Raton, FL, USA, 2015; pp. 125-138.

92. Strzelczyk, A.; Adjei, P.; Scott, C.A.; Bauer, S.; Rosenow, F.; Walker, M.C.; Surges, R. Postictal increase in T-wave alternans after generalized tonic-clonic seizures. Epilepsia 2011, 52, 2112-2117. [CrossRef] [PubMed]

93. Behbahani, S.; Dabanloo, N.J.; Nasrabadi, A.M.; Teixeira, C.A.; Dourado, A. Pre-ictal heart rate variability assessment of epileptic seizures by means of linear and non-linear analyses. Anadolu Kardiyol. Derg. 2013, 13, 797-803. [CrossRef] [PubMed]

94. Boon, P.; Vonck, K.; van Rijckevorsel, K.; Tahry, R.E.; Elger, C.E.; Mullatti, N.; Schulze-Bonhage, A.; Wagner, L.; Diehl, B.; Hamer, H.; et al. A prospective, multicenter study of cardiac-based seizure detection to activate vagus nerve stimulation. Seizure 2015, 32, 52-61. [CrossRef] [PubMed]

95. Larsen, S.N.; Conradsen, I.; Beniczky, S.; Sorensen, H.B. Detection of tonic epileptic seizures based on surface electromyography. In Proceedings of the 2014 36th Annual International Conference of the IEEE Engineering in Medicine and Biology Society, Chicago, IL, USA, 26-30 August 2014; pp. 942-945.

96. Conradsen, I.; Wolf, P.; Sams, T.; Sorensen, H.B.; Beniczky, S. Patterns of muscle activation during generalized tonic and tonic-clonic epileptic seizures. Epilepsia 2011, 52, 2125-2132. [CrossRef] [PubMed]

97. Conradsen, I.; Beniczky, S.; Wolf, P.; Jennum, P.; Sorensen, H.B. Evaluation of novel algorithm embedded in a wearable sEMG device for seizure detection. In Proceedings of the 2012 Annual International Conference of the IEEE Engineering in Medicine and Biology Society, San Diego, CA, USA, 28 August-1 September 2012; pp. 2048-2051. 
98. Poh, M.Z.; Loddenkemper, T.; Swenson, N.C.; Goyal, S.; Madsen, J.R.; Picard, R.W. Continuous monitoring of electrodermal activity during epileptic seizures using a wearable sensor. In Proceedings of the 2010 Annual International Conference of the IEEE Engineering in Medicine and Biology, Buenos Aires, Argentina, 31 August-4 September 2010; pp. 4415-4418.

99. Lockman, J.; Fisher, R.S.; Olson, D.M. Detection of seizure-like movements using a wrist accelerometer. Epilepsy Behav. 2011, 20, 638-641. [CrossRef] [PubMed]

100. Nijsen, T.M.; Aarts, R.M.; Cluitmans, P.J.; Griep, P.A. Time-frequency analysis of accelerometry data for detection of myoclonic seizures. IEEE Trans. Inf. Technol. Biomed. 2010, 14, 1197-1203. [CrossRef] [PubMed]

101. Nijsen, T.M.; Arends, J.B.; Griep, P.A.; Cluitmans, P.J. The potential value of three-dimensional accelerometry for detection of motor seizures in severe epilepsy. Epilepsy Behav. 2005, 7, 74-84. [CrossRef] [PubMed]

102. Jallon, P.; Bonnet, S.; Antonakios, M.; Guillemaud, R. Detection system of motor epileptic seizures through motion analysis with 3D accelerometers. In Proceedings of the 2009 Annual International Conference of the IEEE Engineering in Medicine and Biology Society, Minneapolis, MN, USA, 3-6 September 2009; pp. 2466-2469.

103. Schulc, E.; Unterberger, I.; Saboor, S.; Hilbe, J.; Ertl, M.; Ammenwerth, E.; Trinka, E.; Them, C. Measurement and quantification of generalized tonic-clonic seizures in epilepsy patients by means of accelerometry-An explorative study. Epilepsy Res. 2011, 95, 173-183. [CrossRef] [PubMed]

104. Narechania, A.P.; Garic, I.I.; Sen-Gupta, I.; Macken, M.P.; Gerard, E.E.; Schuele, S.U. Assessment of a quasi-piezoelectric mattress monitor as a detection system for generalized convulsions. Epilepsy Behav. 2013, 28, 172-176. [CrossRef] [PubMed]

105. Lu, H.; Pan, Y.; Mandal, B.; Eng, H.L.; Guan, C.; Chan, D.W. Quantifying limb movements in epileptic seizures through color-based video analysis. IEEE Trans. Biomed. Eng. 2013, 60, 461-469. [CrossRef] [PubMed]

106. Mandal, B.; Eng, H.L.; Lu, H.; Chan, D.W.; Ng, Y.L. Non-intrusive head movement analysis of videotaped seizures of epileptic origin. In Proceedings of the 2012 Annual International Conference of the IEEE Engineering in Medicine and Biology Society, San Diego, CA, USA, 28 August-1 September 2012; pp. 6060-6063.

107. Poh, M.Z.; Loddenkemper, T.; Reinsberger, C.; Swenson, N.C.; Goyal, S.; Sabtala, M.C.; Madsen, J.R.; Picard, R.W. Convulsive seizure detection using a wrist-worn electrodermal activity and accelerometry biosensor. Epilepsia 2012, 53, e93-e97. [CrossRef] [PubMed]

108. American Thoracic Society. Standards and indications for cardiopulmonary sleep studies in children. Am. J. Respir. Crit. Care Med. 1996, 153, 866-878.

109. Marcus, C.L.; Brooks, L.J.; Draper, K.A.; Gozal, D.; Halbower, A.C.; Jones, J.; Schechter, M.S.; Ward, S.D.; Sheldon, S.H.; Shiffman, R.N.; et al. Diagnosis and management of childhood obstructive sleep apnea syndrome. Pediatrics 2012, 130, e714-e755. [CrossRef] [PubMed]

110. Blechner, M.; Williamson, A.A. Consequences of Obstructive Sleep Apnea in Children. Curr. Probl. Pediatr. Adolesc. Health Care 2016, 46, 19-26. [CrossRef] [PubMed]

111. Beebe, D.W.; Wells, C.T.; Jeffries, J.; Chini, B.; Kalra, M.; Amin, R. Neuropsychological effects of pediatric obstructive sleep apnea. J. Int. Neuropsychol. Soc. 2004, 10, 962-975. [CrossRef] [PubMed]

112. Beebe, D.W. Neurobehavioral morbidity associated with disordered breathing during sleep in children: A comprehensive review. Sleep 2006, 29, 1115-1134. [CrossRef] [PubMed]

113. Joosten, K.F.; Larramona, H.; Miano, S.; Van Waardenburg, D.; Kaditis, A.G.; Vandenbussche, N.; Ersu, R. How do we recognize the child with OSAS? Pediatr. Pulmonol. 2016, 52, 260-271. [CrossRef] [PubMed]

114. Chervin, R.D.; Weatherly, R.A.; Garetz, S.L.; Ruzicka, D.L.; Giordani, B.J.; Hodges, E.K.; Dillon, J.E.; Guire, K.E. Pediatric sleep questionnaire: Prediction of sleep apnea and outcomes. Arch. Otolaryngol. Head Neck Surg. 2007, 133, 216-222. [CrossRef] [PubMed]

115. Kirk, V.G.; Bohn, S.G.; Flemons, W.W.; Remmers, J.E. Comparison of home oximetry monitoring with laboratory polysomnography in children. Chest 2003, 124, 1702-1708. [CrossRef] [PubMed]

116. Nixon, G.M.; Kermack, A.S.; Davis, G.M.; Manoukian, J.J.; Brown, K.A.; Brouillette, R.T. Planning adenotonsillectomy in children with obstructive sleep apnea: The role of overnight oximetry. Pediatrics 2004, 113, e19-e25. [CrossRef] [PubMed] 
117. Garde, A.; Dehkordi, P.; Karlen, W.; Wensley, D.; Ansermino, J.M.; Dumont, G.A. Development of a screening tool for sleep disordered breathing in children using the phone Oximeter. PLOS ONE 2014, 9, e112959. [CrossRef] [PubMed]

118. Brouillette, R.T.; Morielli, A.; Leimanis, A.; Waters, K.A.; Luciano, R.; Ducharme, F.M. Nocturnal pulse oximetry as an abbreviated testing modality for pediatric obstructive sleep apnea. Pediatrics 2000, 105, 405-412. [CrossRef] [PubMed]

119. Foo, J.Y.; Lim, C.S. Development of a home screening system for pediatric respiratory sleep studies. Telemed. J. E Health 2006, 12, 698-701. [CrossRef] [PubMed]

120. Waters, K.A.; Forbes, P.; Morielli, A.; Hum, C.; O'Gorman, A.M.; Vernet, O.; Davis, G.M.; Tewfik, T.L.; Ducharme, F.M.; Brouillette, R.T. Sleep-disordered breathing in children with myelomeningocele. J. Pediatr. 1998, 132, 672-681. [CrossRef]

121. Marcus, C.L.; Traylor, J.; Biggs, S.N.; Roberts, R.S.; Nixon, G.M.; Narang, I.; Bhattacharjee, R.; Davey, M.J.; Horne, R.S.; Cheshire, M.; et al. Feasibility of comprehensive, unattended ambulatory polysomnography in school-aged children. J. Clin. Sleep Med. 2014, 10, 913-918. [CrossRef] [PubMed]

122. Goodwin, J.L.; Enright, P.L.; Kaemingk, K.L.; Rosen, G.M.; Morgan, W.J.; Fregosi, R.F.; Quan, S.F. Feasibility of using unattended polysomnography in children for research-Report of the Tucson Children's Assessment of Sleep Apnea study (TuCASA). Sleep 2001, 24, 937-944. [CrossRef] [PubMed]

123. Primeau, M.; Gershon, A.; Talbot, L.; Cotto, I.; Lotspeich, L.; Hardan, A.; Hallmayer, J.; O’Hara, R. Individuals with Autism Spectrum Disorders Have Equal Success Rate But Require Longer Periods of Systematic Desensitization than Control Patients to Complete Ambulatory Polysomnography. J. Clin. Sleep Med. 2016, 12, 357-362. [CrossRef] [PubMed]

(C) 2017 by the authors. Licensee MDPI, Basel, Switzerland. This article is an open access article distributed under the terms and conditions of the Creative Commons Attribution (CC BY) license (http:/ / creativecommons.org/licenses/by/4.0/). 